\title{
Innovative and Competitive Behaviour of Bulgarian Enterprises: Evidence From Empirical Studies in 2007 and 2014
}

\author{
Miroslava Hristova \\ Sofia University "St.Kliment Ohridski”, Sofia, Bulgaria
}

\begin{abstract}
The article describes some patterns observed in firms' innovative and competitive behavior in Bulgaria in empirical studies performed in 2007 and in 2014. The studies covered 131 and 112 firms respectively, functioning on the Bulgarian market, pertaining to diverse sectors and being different size (micro firms, small, medium sized, and large enterprises) and ownership (private and public). Innovative and competitive behaviors were operationalized as parts of the strategic behavior of the firm. Their aggressiveness and optimality have been compared to the necessary one given the level of environment instability. The empirical findings suggest that there are observed patterns of sustained behavior, innovative and competitive, between the two periods.
\end{abstract}

Keywords: strategic behavior, innovative behavior, competitive behavior, Ansoff's framework, empirical study, firms, Bulgaria

\section{Introduction}

Innovative and competitive behaviors represent components of the strategic behavior of a firm, whereby the firm engages in the search of opportunities, the sheltering from strategic surprises, the gaining of profitability, of competitiveness and performance, and the obtaining of competitive advantage. Strategic behavior constitutes thus an active behavior and in its two parts is to be understood as a measure of how well a firm adapts and relates to its external environment (Ansoff, 1965; Ansoff \& McDonnell, 1990). A main postulate in management and strategy is that the adaptation and optimal relating of an enterprise to the factors and requirements of its environment is of prime importance for its competitiveness, performance, and profitability, regardless of the type and size of the enterprise (small, medium, or large; private or public) and the type of environment in which it operates. Whereas the innovative component of the strategic behavior is concerned with the strategic activity of the firm in entrepreneurial aspect, the competitive one is related to the business activity in competitive aspect, complementing and accommodating the innovative one. The present study examines both components of the strategic behavior, over two different periods, 2007 and 2014, with the objective of identifying sustained or different patterns in the strategic behavior of firms in Bulgaria.

\footnotetext{
Miroslava Hristova, Ph.D., associate professor, Faculty of Economics and Business Administration, Department of Business Administration, Sofia University "St.Kliment Ohridski”, Sofia, Bulgaria.

Correspondence concerning this article should be addressed to Miroslava Hristova, Sofia University "St.Kliment Ohridski", Faculty of Economics and Business Administration, 125, Tzarigradsko chaussee, Block 3, Sofia, Bulgaria. E-mail: christova.miroslava@gmail.com.
} 


\section{Theory Development and Prior Research}

\section{Theory Development}

In the theoretical field of strategy, the innovative and competitive behavior pertains to the scientific area of strategic behavior of firms. In this area, the most established framework pertains to Ansoff (1987). The framework, known as the strategic success hypothesis, contingent success formula, or strategic diagnosis model (Ansoff, 1987; 1988; Ansoff \& Sullivan, 1993a; 1993b), is concerned with the strategic behavior of organizations, especially environment serving organizations (ESO), sometimes referred to as purposive organizations (Ansoff \& Sullivan, 1993a; 1993b). Strategic behavior, being understood as a measure of how well a firm adapts and relates to its external environment (Ansoff \& McDonnell, 1990), can alternatively be defined as strategy itself. Nevertheless, the hypothesis sets out a narrow and specific field or school of thought, in the strategic management theory, due to its key concepts-strategic behavior, competitive and entrepreneurial behavior, environmental turbulence, strategic aggressiveness, and general management responsiveness. This success hypothesis states that for optimum profitability, the levels of both the strategic aggressiveness and general management responsiveness of the firm must be aligned with the environmental turbulence level (Ansoff, 1979; Ansoff \& Sullivan, 1993a; 1993b); or the performance of a firm is optimized when its strategic behavior, both innovative and competitive, is aligned with its environment turbulence level (Ansoff, 1979; Ansoff \& Sullivan, 1993a; 1993b). The alignment of a firm's response in its two integral parts, competitive and innovative, to the environmental turbulence, is measured by the respective gaps between the level of turbulence and the level of strategic aggressiveness on one hand, and capability responsiveness level on the other. For optimum performance, both strategy and capability of an ESO must be aligned with the turbulence of the ESO's environment (Ansoff, 1979; Ansoff \& Sullivan, 1993b). Meanwhile, the strategic (innovative and competitive) behavior covers three dimensions, such as the strategy content (the essence of the strategic choices of the firm), the strategy process (the process by which the firm formulates its strategic choices), and the strategic logic of the behavior (the character of being proactive, reactive, systematic, and comprehensive), and others. Different types and categories of strategic behavior can accordingly be observed in theory and practice of firms, each type of strategic behavior being relevant and appropriate, for optimal firm performance, under different environmental turbulence level (Ansoff, 1979; Ansoff \& Sullivan, 1993a; 1993b).

\section{Prior Research}

Since its formulation, the strategic success hypothesis has been tested in several contexts from 1984 to 1992 (Ansoff \& Sullivan, 1993a; 1993b) and extensively in the 1990s and 2000s, as shown in Table 1. Having been validated through many empirical studies and in various contexts (Ansoff et al., 1993; Hristova, 2007), the strategic diagnosis model has been established as a theory on the strategic behavior of firms in its two parts.

\section{The "Conceptual Umbrella"}

According to its author, the strategic success formula provided a "conceptual umbrella" which accommodated (apparently) contradictory success prescriptions from distinguished management scientists in the management literature, by identifying the environmental turbulence levels at which the respective formulas for success became valid (Ansoff \& Sullivan, 1993a; 1993b). As such, all prescriptions or formulas for success, previously discovered or formulated, by academics or managers, are valid, but under different environmental conditions. The conditions under which each formula becomes successful were also categorized (Ansoff \& Sullivan, 1993a; 1993b). 


\section{The Implications for Both Research and Practice of Strategic Management}

The strategic success hypothesis subsumes two key hypotheses which have important implications to both research and the practice of strategic management (Ansoff \& Sullivan, 1993a; 1993b). These are:

SSH-1: There is no single strategic behavior which assures success;

SSH-2: Environmental turbulence is the driving variable which determines the type of strategic behavior which will succeed in an environment.

Table 1

Empirical Research on the Strategic Diagnosis Model

\begin{tabular}{|c|c|c|}
\hline Project & Researcher/Year & Title \\
\hline 1 & Hatziantoniou (1986) & $\begin{array}{l}\text { The relationship of environmental turbulence, corporate strategic profile and company } \\
\text { performance } \\
\text { (The United States) }\end{array}$ \\
\hline 2 & Chabane (1987) & $\begin{array}{l}\text { Restructuring and performance in Algerian state-owned enterprises: A strategic } \\
\text { management study } \\
\text { (Algeria) }\end{array}$ \\
\hline 3 & Sullivan (1987) & $\begin{array}{l}\text { The relationship between proportion of income derived from subsidy and strategic } \\
\text { performance of a federal agency under the commercial activities program } \\
\text { (The United States) }\end{array}$ \\
\hline 4 & Salameh (1987) & $\begin{array}{l}\text { Strategic posture analysis and financial performance of the banking industry in the United } \\
\text { Arab Emirates: A strategic management study } \\
\text { (UAE) }\end{array}$ \\
\hline 5 & Lewis (1989) & $\begin{array}{l}\text { Strategic posture and financial performance of the banking industry in California: A } \\
\text { strategic management study } \\
\text { (The United States) }\end{array}$ \\
\hline 6 & Gutu (1989) & $\begin{array}{l}\text { An investigation of environmental dependence hypothesis in state-owned corporations } \\
\text { (parastatals) in Kenya: A strategic management perspective } \\
\text { (Kenya) }\end{array}$ \\
\hline 7 & Jaja (1989) & $\begin{array}{l}\text { Technology and banking: The implications of technological change on the financial } \\
\text { performance of commercial banks } \\
\text { (The United States) }\end{array}$ \\
\hline 8 & Thorsell (1990) & $\begin{array}{l}\text { A framework for determination of strategies for general manager transformational } \\
\text { development } \\
\text { (The United States) }\end{array}$ \\
\hline 9 & Wang (1991) & $\begin{array}{l}\text { Determinants of perceptions of environmental turbulence and strategic response of } \\
\text { savings and loan top managers } \\
\text { (The United States) }\end{array}$ \\
\hline 10 & Djohar (1991) & $\begin{array}{l}\text { The relationships between strategic effectiveness, competitive efficiency and } \\
\text { performance in Indonesian firms } \\
\text { (Indonesia) }\end{array}$ \\
\hline 11 & Mitiku (1992) & $\begin{array}{l}\text { The relationships between strategic factors and the performance of state-owned industrial } \\
\text { enterprises in Ethiopia } \\
\text { (Ethiopia) }\end{array}$ \\
\hline 12 & Al-Hadramy (1992) & $\begin{array}{l}\text { General managers' personality characteristics and perceptions of environmental } \\
\text { turbulence as related to rationality of strategic choice in small firms } \\
\text { (The United States) }\end{array}$ \\
\hline 13 & Achua (1992) & $\begin{array}{l}\text { Relationship between selected strategic project management factors and performance of } \\
\text { project groups of manufacturing and/or service businesses } \\
\text { (The United States) }\end{array}$ \\
\hline 14 & Taylor (1992) & $\begin{array}{l}\text { Factors and behaviors associated with successful technology substitution decisions in the } \\
\text { high turbulence environment } \\
\text { (The United States) }\end{array}$ \\
\hline 15 & Chafie (1992) & $\begin{array}{l}\text { The relationships between top management information system profiles, managerial } \\
\text { capability and environmental turbulence } \\
\text { (The United States) }\end{array}$ \\
\hline
\end{tabular}


Table 1 continued

\begin{tabular}{|c|c|c|}
\hline Project & Researcher/Year & Title \\
\hline 16 & Lombriser (1992) & $\begin{array}{l}\text { Impact of general manager leadership behavior on success of discontinuous strategic } \\
\text { changes in thirty Swiss business firms } \\
\text { (Switzerland) }\end{array}$ \\
\hline 17 & Choi (1993) & $\begin{array}{l}\text { The relationships between strategic factors and performance of diversified firms and their } \\
\text { strategic business units in Japan } \\
\text { (Japan) }\end{array}$ \\
\hline 18 & Camelia (1993) & $\begin{array}{l}\text { Perceived impact of different types of European Community regulations on performance } \\
\text { of business firms in the Netherlands } \\
\text { (Netherlands) }\end{array}$ \\
\hline 19 & Thabet (1993) & $\begin{array}{l}\text { The relationship between strategic choice of technology and success of technology } \\
\text { transfer to local firms in less developed countries: The case of Yemen } \\
\text { (Yemen) }\end{array}$ \\
\hline 20 & Freidank (1994) & $\begin{array}{l}\text { Managing transformational change in German business firms } \\
\text { (Germany) }\end{array}$ \\
\hline 21 & Johannesson (1994) & $\begin{array}{l}\text { The relationships among strategic intelligence aggressiveness, capability and the success } \\
\text { of strategic intelligence function } \\
\text { (The United States) }\end{array}$ \\
\hline 22 & Schulze (1994) & $\begin{array}{l}\text { Differences of corporate management behavior to foster success of intrapreneurs in } \\
\text { charge of incremental or discontinuous innovations } \\
\text { (The United States) }\end{array}$ \\
\hline 23 & Moussetis (1996) & $\begin{array}{l}\text { The relationships between legitimacy posture, rules of the game and performance of the } \\
\text { firm } \\
\text { (The United States) }\end{array}$ \\
\hline 24 & Gabriel (1996) & $\begin{array}{l}\text { An empirical assessment of a predictive theory of resistance to transformational change } \\
\text { in environment-serving organizations } \\
\text { (The United States) }\end{array}$ \\
\hline 25 & Levitt (1997) & $\begin{array}{l}\text { Acquisition and assimilation of management skills by Chinese light industrial firms: Soft } \\
\text { technology transfer to a transnational economy } \\
\text { (China) }\end{array}$ \\
\hline 26 & Velten (1997) & $\begin{array}{l}\text { The relationships between corporate general management behavior and the success of } \\
\text { strategic portfolio management in German business firms } \\
\text { (Germany) }\end{array}$ \\
\hline 27 & Chartier (1998) & $\begin{array}{l}\text { Strategic leadership: Product and technology innovation in high-technology companies } \\
\text { (The United States) }\end{array}$ \\
\hline 28 & Abu-Rahma (1999) & $\begin{array}{l}\text { The relationships among national culture, strategic aggressiveness, capability and } \\
\text { financial performance: The case of banks in Jordan and the United States } \\
\text { (Jordan) }\end{array}$ \\
\hline 29 & Coop (1999) & $\begin{array}{l}\text { The relationship between decision style and power source used in decision-making and } \\
\text { strategic success in Christian churches } \\
\text { (The United States) }\end{array}$ \\
\hline 30 & Han (1999) & $\begin{array}{l}\text { The relationship between environmental turbulence, top manager mindset, organization } \\
\text { culture, power and performance in Korean firms } \\
\text { (Korea) }\end{array}$ \\
\hline 31 & Jihwan (2000) & $\begin{array}{l}\text { The relationships among environmental turbulence, strategic aggressiveness of } \\
\text { information technology, organizational information technology capability, and } \\
\text { organizational performance } \\
\text { (The United States) }\end{array}$ \\
\hline 32 & Hristova (2007) & $\begin{array}{l}\text { Strategic management in a transition country: The case of Bulgaria } \\
\text { (Bulgaria) }\end{array}$ \\
\hline 33 & Hristova (2009) & $\begin{array}{l}\text { Comparative analysis of the strategic behavior of enterprises in Bulgaria and France and } \\
\text { of its impact on enterprises' performance } \\
\text { (Bulgaria and France) }\end{array}$ \\
\hline
\end{tabular}

\section{Research Methodology}

The research studied the two parts of the strategic behavior (the innovative and the competitive) and its 
three dimensions (the strategy process, the strategy content, and the dominant logic) of Bulgarian firms in two periods, 2007 and 2014. Types of the strategic behavior, the aggressiveness of firms' strategic behavior, given the respective turbulence level of the external environment, and patterns of sustained behavior in the two periods, were also explored. The empirical studies were performed by the method of standardized questionnaires.

\section{Research Questionnaire and Data Collection}

The descriptive theoretical language of the strategic success hypothesis or diagnosis model (Ansoff, 1988; Ansoff \& Sullivan, 1993a; 1993b; Ansoff \& McDonnell, 1990) was translated into a questionnaire, which included distinct groups of questions covering: the entrepreneurial part, the competitive part, the strategy process, the strategy content, the dominant logic of the behavior, the types of strategic behaviors, the strategic aggressiveness, and the environment characteristics of the firm.

The questionnaire was first elaborated in 2007 and with minor clearances for misunderstandings and improvements, it has been repeated in 2014.

\section{Sampling Procedures and Sample Characteristics}

For the sampling procedures in both studies, the study has relied on a sociologic agency in the framework of a research project. In 2007, the research took place under the research project "analysis of firm's strategies in Bulgaria", and in 2014 under "analysis of firm's strategic issues in Bulgaria and possible ways of overcoming them". The response rates were approximately $21 \%$ and $27 \%$ respectively. Different numbers of samples were obtained for the two studies - 131 and 112, respectively, representing a wide range of industries, sizes, and firm ownership.

\section{Results of the Studies}

\section{Patterns in the Innovative Behavior of Bulgarian Firms: Strategy Content}

As integral part of the strategic behavior, the strategy content and process in the studied firms take the form of formulation of a strategy both in 2007 and 2014. Firms in their greatest majority indicate that they have formulated a strategy for the achievement of their goals (Table 2). However, from one period to the second, a decreasing number of firms have formulated a strategy.

Table 2

Strategy Formulation by the Firm

\begin{tabular}{lcc}
\hline & 2007 & 2014 \\
\hline Having formulated a strategy for the achievement of their goals & $92.4 \%$ & $85.7 \%$ \\
Not having formulated a strategy for the achievement of goals & $5.6 \%$ & $14.3 \%$ \\
\hline In the cases of strategy formulation: & & \\
\hline Strategy is rendered explicit in a document & $51.1 \%$ & $61.6 \%$ \\
Is not documented & $48.1 \%$ & $38.4 \%$ \\
\hline
\end{tabular}

In the cases of strategy formulation, the strategy is typically rendered explicit in a document in about half of the firms in 2007 and in more than half of the firms in 2014.

Firms that do not render explicit their strategy show lessening number in the period of seven years. As for the types of strategies developed, they are, in the greatest majority of cases in 2007 and 2014, concrete strategies to be followed as a precise guide by the studied firms. In a second group, growing are the lots of 
firms lacking a formulated strategy, with as nearly as three times between 2007 and 2014 .

An observed pattern regarding firms' strategic choices and thus their innovative behavior is that both in 2007 and 2014, the majority of the studied firms indicate that they have adopted more than one strategy.

The mostly followed are the strategies of diversification, the strategy of internationalization, the local/regional strategy, the strategy on the national level, the international strategy, the global strategy, and the strategy of survival. In 2007, the majority of firms pursuit the strategy of expansion; by 2014, this strategy marks a nearly twofold decrease, while the strategy of liquidation of activities - an expressed increase, but together with another expressed rise, that of the global strategy.

As Table 3 shows, other strategies firms do not adopt much in the first period, but what are more represented in the second are the strategies for the creation of clusters and participation in networks of firms, and the outsourcing strategy. The strategy for strategic alliances has nevertheless decreased in adoption, letting place for the outsourcing and other forms of cooperation.

Other highly represented strategies are the strategy aimed at social goals and the one aimed at ecological goals. The strategy for the activities of the firm is less presented in the second observations, as is the strategy for the agents with whom the firm cooperates.

Table 3

Corporate Strategies of the Firm

\begin{tabular}{lcc}
\hline & 2007 & 2014 \\
\hline Diversification strategy & $35.1 \%$ & $42.9 \%$ \\
Local/regional strategy & $21.4 \%$ & $33.0 \%$ \\
Strategy on the national level & $61.1 \%$ & $22.3 \%$ \\
International strategy & $26.7 \%$ & $30.4 \%$ \\
Global strategy & $3.1 \%$ & $16.1 \%$ \\
Strategy of internationalization & $12.2 \%$ & $33.9 \%$ \\
Strategy for survival & $12.2 \%$ & $19.6 \%$ \\
Strategy of expansion & $54.2 \%$ & $24.1 \%$ \\
Strategy of liquidation of activities & $0.8 \%$ & $10.7 \%$ \\
Strategy for the creation of clusters, participation in networks of firms & $6.0 \%$ & $11.6 \%$ \\
Strategy for strategic alliances & $9.2 \%$ & $6.3 \%$ \\
Outsourcing strategy & $8.4 \%$ & $16.1 \%$ \\
Strategy aimed at social goals & $51.9 \%$ & $21.4 \%$ \\
Strategy aimed at ecological goals & $13.7 \%$ & $21.4 \%$ \\
Strategy for the activities of the firm & $32.8 \%$ & $17.0 \%$ \\
Strategy for the agents of cooperation of the firm & $26.0 \%$ & $13.4 \%$ \\
\hline
\end{tabular}

Patterns in the Innovative and Competitive Behavior of Bulgarian Firms: Strategic Analysis of the External Environment

Among the strategic analyses of the external environment, the studied firms indicate, in the majority of cases, the analysis of data and short-term forecasts (strong signals management), the economic forecasts for the trends in the environment, the opportunities and threats, and about $1 / 3$ of the firms - the forecasts elaboration (Table 4). Other widely performed analyses are the competitors' intelligence and the analysis of sayings-hearing for the development of the business environment (weak signal management). 
Greatly gaining use is the brainstorming, more than doubling between the two studies, and decreasing in adoption are the scenarii for the development of the macroeconomic environment in short or long term. The industrial or technological intelligence and the analysis of the five forces (by Porter's model) also increase in use, at the expense of the simulations.

By their estimations for the external environment in 2007, the firms point out levels of turbulence comprised between 1.91 and 3.64, by the method of Ansoff (1988) and Ansoff and McDonnell (1984). In 2014, by the same method, the levels of turbulence are between 1.53 and 3.45. The behaviors considered optimal with regard to the potential firm performance are thus situated in the range from the capital budgets to the periodic strategic planning.

Table 4

Strategic Analysis of the External Environment

\begin{tabular}{lrr}
\hline & 2007 & 2014 \\
\hline Economic forecasts for the trends in the environment, the opportunities and threats & $35.9 \%$ & $50.0 \%$ \\
Analysis of data and short-term forecasts (strong signal) & $15.3 \%$ & $58.9 \%$ \\
Scenarii for the development of the macroeconomic environment in short or long term & $28.2 \%$ & $18.8 \%$ \\
Industrial or technological intelligence & $4.6 \%$ & $8.9 \%$ \\
Competitors' intelligence & $15.3 \%$ & $25.9 \%$ \\
Analysis of the five forces (Porter's) & $6.9 \%$ & $13.4 \%$ \\
Analysis of sayings-hearing for the development of the business environment (weak signal) & $13.7 \%$ & $25.9 \%$ \\
Brainstorming & $12.2 \%$ & $31.3 \%$ \\
Simulations & $9.9 \%$ & $8.0 \%$ \\
Forecasts elaboration & $33.6 \%$ & $36.6 \%$ \\
None of the above & $5.3 \%$ & $5.4 \%$ \\
\hline
\end{tabular}

Patterns in the Innovative and Competitive Behavior of Bulgarian Firms: Strategic Analysis of the Internal Environment

Among the strategic analyses of the internal environment, a steady application over the two periods possesses the evaluation of the firms' strengths, weaknesses, and capabilities, marking even an increase from 2007 to 2014 (Table 5).

Firms clearly see the strengths and their evaluation as a ground for a successful strategy, even in the short term. The scenarii for the development of the firm in the short or long term are also very used by the firms in both studies and show an important increase. The benchmarking is more doubling its adoption, while the portfolio analysis remains stable in application in both 2007 and 2014.

Table 5

Strategic Analysis of the Internal Environment

\begin{tabular}{lll}
\hline & 2007 & 2014 \\
\hline Evaluation of the strengths and weaknesses, of firms' capabilities & $61.1 \%$ & $74.1 \%$ \\
Portfolio analysis & $13.7 \%$ & $13.4 \%$ \\
Scenarii for the development of the firm in the short or long term & $52.7 \%$ & $61.6 \%$ \\
Benchmarking & $11.5 \%$ & $25.0 \%$ \\
\hline
\end{tabular}




\section{Patterns in the Competitive Behavior of Bulgarian Firms: Business Strategy}

As Table 6 indicates, the business strategies firms implemented in 2007 are the strategy-price for nearly half of the firms and the strategy of differentiation for $1 / 3$ of the firms. These two strategies are even more applied in the second period.

At the same time, in both 2007 and 2014, the strategy of innovations is indicated by nearly half of the firms. In 2014, a clear increase in the niche strategy was observed, which attains application in more than $1 / 3$ of the studied firms.

Table 6

Business Strategies of the Firm

\begin{tabular}{|c|c|c|}
\hline & 2007 & 2014 \\
\hline Strategy-price & $48.1 \%$ & $60.7 \%$ \\
\hline Strategy of differentiation & $33.8 \%$ & $39.3 \%$ \\
\hline Niche strategy & $35.1 \%$ & $43.8 \%$ \\
\hline Strategy of innovations & $51.1 \%$ & $49.1 \%$ \\
\hline
\end{tabular}

Patterns in the Competitive and Innovative Behavior of Bulgarian Firms: Strategy Process

With regard to the strategy process, about $1 / 3$ of the studied firms in both periods develop concrete strategies to be followed as a broad guide. Between 2007 and 2014, however, growing is the number of firms indicating that they have developed concrete strategies to be followed as a precise guide (Table 7).

Table 7

Strategy Development of the Firm

\begin{tabular}{lll}
\hline & 2007 & 2014 \\
\hline Concrete strategies, to be followed as a broad guide & $32.7 \%$ & $30.4 \%$ \\
Concrete strategies, to be followed as a precise guide & $38.2 \%$ & $46.4 \%$ \\
Lack of a formulated strategy & $21.4 \%$ & $31.3 \%$ \\
\hline
\end{tabular}

Also growing is the number of firms lacking a formulated strategy with regard to the strategy process, which is consistent with replies of firms elsewhere, for example, in the strategy content side and the formulation of strategy for the achievement of firm's goals.

From the first study to the second, the strategic plan of the firm has been found to include less long-term goals and objectives and considerably more short-term goals and objectives. As shown in Table 8 , the documentation of the goals/objectives is typical for a considerable part of the firms in both studies. From 2007 to 2014, the goals/objectives of firms grow less flexible and permitting modification in larger part of the firms, becoming more fixed and not allowing modifications until achieved.

The overall number of more than 10 for the goals or objectives marks a strong decrease between 2007 and 2014 , in favor of the overall number of up to five goals/objectives, which nearly doubles in 2014 (Table 9). The goals/objectives between five and 10 remain steadily represented as 1/4 of the cases in both 2007 and 2014 .

Over both periods, the types of goals/objectives included in the strategic plans of the firms are mainly statements of specific financial targets, to be achieved either annually or over the foreseeable future, together with statements of specific market share/sales growth targets for the firm, for more than half of the cases. As Table 10 shows, in the two studies, firms' plans also include broad statements of key strategic goals or 
objectives for the firms which tend to change or evolve as circumstances warrant. Less indicated are statements of specific key result areas/objectives for many/all functions/operations of the firm, decreasing between 2007 and 2014, and broad statements of key strategic goals/objectives for the firm and which tend not to change/evolve as circumstances warrant.

Table 8

The Strategic Plan of the Firm and the Types of Goals/Objectives of Firms

\begin{tabular}{llc}
\hline & 2007 & 2014 \\
\hline Goals/objectives of firms: & & \\
\hline Long-term & $61.1 \%$ & $42.9 \%$ \\
Short-term & $34.4 \%$ & $52.7 \%$ \\
Documented & $47.3 \%$ & $42.9 \%$ \\
Not explicited in a document & $32.1 \%$ & $29.5 \%$ \\
Flexible; permitting modification & $71.8 \%$ & $65.2 \%$ \\
Fixed; not permitting modifications until achieved & $10.7 \%$ & $20.5 \%$ \\
\hline
\end{tabular}

Table 9

The Strategic Plan of the Firm and the Overall Number of Goals/Objectives

\begin{tabular}{lll}
\hline Overall number of goals/objectives & 2007 & 2014 \\
\hline Under 5 & $31.3 \%$ & $58.9 \%$ \\
Between 5 and 10 & $24.4 \%$ & $25.9 \%$ \\
More than 10 & $25.2 \%$ & $14.3 \%$ \\
\hline
\end{tabular}

Table 10

The Strategic Plan of the Firm and Firms' Objectives

\begin{tabular}{lll}
\hline & 2007 & 2014 \\
\hline $\begin{array}{l}\text { Broad statements of key strategic goals/objectives for the firm, which tend not to change/evolve as } \\
\text { circumstances warrant }\end{array}$ & $17.6 \%$ & $14.3 \%$ \\
Broad statements of key strategic goals/objectives for the firm, which tend to change/evolve & $55.7 \%$ & $48.2 \%$ \\
Statements of specific financial targets to be achieved, either annually, or over the foreseeable & $52.7 \%$ & $63.4 \%$ \\
future & $58.8 \%$ & $55.4 \%$ \\
Statements of specific market share/sales growth targets for the firm & $31.3 \%$ & $25.0 \%$ \\
Statements of specific key result areas/objectives for many/all functions/operations of the firm & & \\
\hline
\end{tabular}

\section{Patterns in the Innovative and Competitive Behavior of Bulgarian Firms: Dominant Logic}

In 2007, the strategic actions mostly never precede the strategic decisions, with nearly half of the studied firms; in 2014, their number has declined to about 1/4 of the firms (Table 11). Instead, for a growing number of firms, strategic decisions precede strategic actions either occasionally, sometimes, or often, the last with a fivefold increase.

While the optimal types of firms' strategic behavior range from capital budgets to periodic strategic planning in Ansoff's framework sense (1988), the studied firms have mostly adopted, in 2007 as well as in 2014, the behaviors of strategy formulation for the development of the firm, management by objectives, analysis and planning of the current capabilities of the firm, analysis and planning of new capabilities of the firm, strategic planning, and strategic management (Table 12). In terms of the strategic success hypothesis (Ansoff, 1988), these behaviors are more aggressive than needed for optimal firm performance. One strategic 
type of behavior - the long range planning - fits the optimal range and is being adopted by half of the firms in 2007. In 2014, it has lost application, falling down to the mere $2.7 \%$.

Other elements or types of strategic behavior strongly adopted by the firms are the observation of actual familiar changes and trends in the environment (strong signal management), the management by extrapolation, and the strategic learning. While the former two types lose application between the two periods, the latter gains in application (Table 13).

Table 11

Strategic Actions of the Firm

\begin{tabular}{lrc}
\hline & 2007 & 2014 \\
\hline Never precede strategic decisions & $44.3 \%$ & $24.1 \%$ \\
Occasionally precede strategic decisions & $29.8 \%$ & $31.3 \%$ \\
Sometimes precede strategic decisions & $23.7 \%$ & $30.4 \%$ \\
Often precede strategic decisions & $1.5 \%$ & $8.0 \%$ \\
Always precede strategic decisions & $0.0 \%$ & $3.6 \%$ \\
\hline
\end{tabular}

Table 12

Types of Strategic Behavior, Innovative and Competitive, Mostly Applied by the Firms

\begin{tabular}{lcc}
\hline & 2007 & 2014 \\
\hline Management by objectives & $59.5 \%$ & $67.0 \%$ \\
Long range planning & $49.6 \%$ & $2.7 \%$ \\
Strategic management & $19.8 \%$ & $52.0 \%$ \\
Strategy formulation for the development of the firm as a whole & $96.2 \%$ & $88.4 \%$ \\
Strategic planning & $85.5 \%$ & $46.40 \%$ \\
Analysis and planning of the current capabilities of the firm & $61.8 \%$ & $61.6 \%$ \\
Analysis and planning of the development of new capabilities of the firm & $52.7 \%$ & $64.3 \%$ \\
\hline
\end{tabular}

Table 13

Other Types of Strategic Behavior, Innovative and Competitive, Applied by the Firms

\begin{tabular}{lll}
\hline & 2007 & 2014 \\
\hline Strong signal management & $39.7 \%$ & $30.4 \%$ \\
Management by extrapolation & $44.3 \%$ & $10.7 \%$ \\
Strategic learning & $42.7 \%$ & $49.1 \%$ \\
\hline
\end{tabular}

In 2007, there are several elements and behaviors that are not applied at all in the studied firms, but that grow in application in 2014. As shown in Table 14, this is the case with the weak signal management, the strategic surprises management, and the abandonment of the historical logic of development of the firm and determination of a new direction.

The strategic surprises management grows from not being adopted in more than half of the firms in 2007 to being adopted in nearly $1 / 10$ of them in 2014. The observation of changes and trends in the environment still little known of rises from largely not applied to applied in nearly $1 / 5$ of the firms, together with the abandonment of the historical logic of development of the firm, shows a minor yet similar pattern between the two periods. 
Table 14

Types of Strategic Behavior, Innovative and Competitive, Not at All Applied in the Firms

\begin{tabular}{lrr}
\hline & 2007 & 2014 \\
\hline Weak signal management & $42.7 \%$ & $17.0 \%$ \\
Strategic surprises management & $52.7 \%$ & $8.9 \%$ \\
The determination of a new direction & $43.5 \%$ & $35.7 \%$ \\
\hline
\end{tabular}

Formulated strategies are mostly allowed to change during their implementation, both in 2007 and 2014 (Table 15). However, from the first study to the second, the firms allowing these changes or modifications are less.

The number of firms that do not allow for modifications and changes during implementation grows more than nine times.

The periods at which changes or modifications in strategies usually take place are at about every six or 12 months, for more than 1/5 of the firms in 2014 (Table 16). Consequently, from 2007 to 2014, the period of changes or modifications in firms' strategies has passed from every three to five years, and about every six month, to about six or 12 months in the majority of firms.

Table 15

Strategy Modification or Change

\begin{tabular}{lcc}
\hline & 2007 & 2014 \\
\hline Modifications or changes in strategy are allowed, during their implementation & $86.3 \%$ & $71.4 \%$ \\
No modifications or changes in strategy are allowed during their implementation & $3.8 \%$ & $28.6 \%$ \\
\hline
\end{tabular}

Table 16

Frequency of Strategy Modification or Change

\begin{tabular}{lrr}
\hline & 2007 & 2014 \\
\hline At about every 6 months & $9.9 \%$ & $21.4 \%$ \\
At about every 12 months & & $21.4 \%$ \\
At about every 3-5 years & $9.9 \%$ & $5.4 \%$ \\
At about every 5-10 years & & $0.9 \%$ \\
Never changes & & $2.7 \%$ \\
Can not answer & $8.4 \%$ & \\
\hline
\end{tabular}

Regarding the reasons for the strategy changes or modifications, one particular main reason in 2007 is the accession to the EU, while in 2014, it is the period of post-financial and economic crisis (Table 17). Maintained in firms' strategic behavior is the trend that other modifications are implied by the perceived important threats in the external environment of firms, as well as opportunities in the environment.

Growing in importance are the internal changes in firms as reasons for firms' strategies changes or modifications. Also increasing from 2007 to 2014 are the planned changes, while steadily represented are the changes that have happened randomly. The lack of changes or modifications firms' strategies is decreasing nearly five times between 2007 and 2014 .

The trends with regard to the optimality of firms' strategic behavior, innovative and competitive, can be summarized in the following parts. 
In 2007, the superior strategic aggressiveness prevails among the types, with more than half of the firms, followed by the highly superior one, with nearly $1 / 5$ of them (Table 18). In 2014, these are replaced by the optimal, and the superior strategic aggressiveness, respectively with nearly half of the firms and more than $1 / 4$ of them. The highly superior strategic aggressiveness is even a stronger and steady characteristic of the firms in 2014, with more than $1 / 5$ of the studied firms. Sustainable is the little percentage of firms that show highly inferior strategic aggressiveness for both periods. Moreover, the tests of the strategic success hypothesis of Ansoff $(1987$; 1988) for the context of Bulgaria show that the strategic success hypothesis has not been supported for any of the two studies.

Table 17

Reasons for Strategy Modification or Change

\begin{tabular}{lcc}
\hline Reasons for the strategy modification or change & 2007 & 2014 \\
\hline Bulgaria's accession to the EU & $26.0 \%$ & $55.4 \%$ \\
The post-financial and economic crisis & $41.1 \%$ \\
Opportunities in the external environment & $50.0 \%$ \\
Threats in the external environment & $25.2 \%$ & $33.0 \%$ \\
Internal changes in the firm & $22.1 \%$ & $27.7 \%$ \\
Planned changes & $16.8 \%$ & $13.4 \%$ \\
Changes happened randomly & $13.7 \%$ & $0.9 \%$ \\
There have not been changes or modifications & $6.1 \%$ & \\
\hline
\end{tabular}

Table 18

Optimality of Strategic Behavior, Innovative and Competitive, of Firms

\begin{tabular}{lrr}
\hline Aggressiveness $<-->$ Environment & 2007 & 2014 \\
\hline Highly superior strategic aggressiveness & $18.3 \%$ & $21.4 \%$ \\
Superior strategic aggressiveness & $52.7 \%$ & $26.7 \%$ \\
Optimal strategic aggressiveness & $8.4 \%$ & $49.1 \%$ \\
Inferior strategic aggressiveness & $9.1 \%$ & $0.9 \%$ \\
Highly inferior strategic aggressiveness & $3.8 \%$ & $0.9 \%$ \\
Superior than needed strategic aggressiveness & $71.0 \%$ & $50.0 \%$ \\
\hline
\end{tabular}

\section{Discussion of Findings}

From the perspective of strategic management, from 2007 to 2014, the most visible and important trend is the change in the nature of firms' external environment. From a stable environment of sustained growth, in 2007, it has evolved to a global financial and economic crisis and a post-crisis period. Therefore, it is relevant to aim to explain observed trends and characteristics of firms' strategic behavior, innovative and competitive, at the light of this change of the environment from one type to another-from the opportunities and perspectives for performance and expansion of Bulgarian firms to the much more morose business climate and perspectives of uncertainty. Instability, less predictability of the future and more threats in the external environment have become the maître-mots, together with institutional and political upheavals and recession. In this context, based on the empirical results, authors identify firms' strategic behavior as being sustainably superior in its strategic aggressiveness both in 2007 and 2014 (Table 19); the trend is, however, stronger in 2007 than that in 2014. 
Table 19

Major Types of Sustained and Less Sustained Strategic Behavior, Innovative and Competitive, of Firms, 2007 and 2014

\begin{tabular}{|l|l|}
\hline Patterns of sustained strategic behavior-especially in: & Patterns of less sustained behavior in: \\
\hline Superior strategic aggressiveness than needed & Goals/objectives of firms_-from long to short term \\
\hline Strategy formulation & Modifications or changes in strategy_less allowed \\
\hline Strategy-price & Strategic actions — precede more often strategic decisions \\
\hline Analysis and planning of the current capabilities & \\
\hline Analysis and planning of the development of new capabilities & \\
\hline Strategic learning & \\
\hline
\end{tabular}

Back in 2007, this superiority of strategic aggressiveness was quite specific, particularly because the instability of the external environment of firms did not require that kind of aggressiveness (in the sense of Ansoff, 1987). This tendency of superior strategic aggressiveness can be seen as far more normal in 2014, given the characteristics of the external environment of firms in that period. Between the two periods, one can speculate if internal reasons do not interfere for decreasing the aggressiveness, such as growing lack of funds and resources to maintain it, concern about a survival need for constant adaptation absorbing some of the strategic activity of renewing the products, etc.

Apart from the major characteristic of the firms' behavior, some elements remain sustainably a part of it, such as, the analysis and the planning of the current capabilities, the management by objectives, and the development of new capabilities. On the downside, there is the strategic planning, for which a nearly twofold decrease occurs as type of behavior for the second period. The strong signal management and the management by extrapolation have also lessened in application.

In 2014, among the types of behavior growing in adoption is the strategic management, from nearly $1 / 5$ of the firms to more than half of the firms. As a second one, the strategic learning, increasing between the two periods and reflecting maybe a perceived growing instability in the external environment of firms.

The types of strategies adopted by firms might be a further clue as to the perceived threats coming from the external environment. The growing number of internationalization strategies, together with the preference of functioning at the local and regional market instead of the national level, the diversification strategy, might be undertaken not so much of growing resources or opportunities, than of defensive strategies of Bulgarian firms, expressing a growing need to seek opportunities elsewhere than at the national market. Next, the downsizing or liquidating activities, growing between the two studies, are putting a term to the trend of expansion of firms frequently observed in 2007. The strategy of strategic alliances has decreased in adoption, letting place for other two types of strategies - participation in networks and clusters, and outsourcing strategies - as a prospective means of trying to survive and gain knowledge, resources, and potential to achieve a competitive advantage.

The strategy of innovations is observed in half of the studied firms both in 2007 and 2014. It can be speculated that while in 2007 the driving factors behind this strategy were the opportunities before these firms, in 2014, it is more the necessity or a possible threat, so this strategy is a means of adaptation and trying to do with less resources.

The same could be affirmed for the strategy-price, which also increases in adoption over the two periods: the strategy of differentiation that reaches roughly $40 \%$ of application; the niche strategy exceeding the $40 \%$, 
all meaning attempts of firms to achieve some advantages in highly difficult conditions of the business environment or to search for a favorable position on a market crowded by competitors. In these unfavorable conditions, the strategic analyses of the external environment which are the most increasing in adoption are the economic forecasts and the analysis of data and short-term forecasts, putting the accent on the external environment and the short-term.

On this background, the trend of a growing number of firms which do not formulate a strategy is understandable. Firms might be in the optics of "wait and see", not sure as to what direction to give to their firm. The strategic actions that always precede the strategic decisions in 2014 in more than one firm might be another confirmation of this optics and an indicator of a perceived growing turbulence of the business environment, wherein firms find it not possible to formulate a strategy and plan for a long period ahead.

When they do formulate a strategy, growing is the number of firms which render explicit their strategy. Besides, more than the majority of the firms are applying steadily the strategic planning in 2014 and in 2007. Is this an evidence for heritage from the practices and managing from the previous socialist period, and their mark on the functioning of firms? Is this an adaptation to new business practices or models applied by Western European or American firms? Is it the influence of academic courses in strategic planning and management that is seen behind these trends? This is a characteristic that needs to be further explored in order to be better explained.

Another trend regarding the strategic plans is that these and the strategies themselves acquire more financial indicators' orientation and short-term focus. The goals/objectives included in the strategic plans are more statements of specific market share/sales growth targets for the firm, or either broad statements of key strategic goals or objectives for the firms. Besides, twofold is in 2014, the increase in the number of fixed goals not permitting modification until achieved. In fact, short-term goals and objectives of the firm are considerably increasing at the expense of the long-term ones. It is not strange therefore, that in the short term, the goals and objectives are not subject to modifications. In addition, the number of firms that do not allow for modifications and changes in the formulated strategy until achieved grows up more than nine times from 2007 to 2014. This is consistent with the indicated period of changes or modifications in firms' strategies: It has passed from "every three-five years" and from "about every six month" to "about six months" or "about 12 months" in the majority of the cases. This trend is however not exclusive and the indications of lack of changes or modifications decrease nearly five times between 2007 and 2014. A nearly doubling of the number of firms which formulate under five goals/objectives is also observed, as well as the two times lesser the number of firms formulating more than 10 goals/objectives between the two periods.

All these tendencies tell, consequently, that either firm chooses more short-term strategies and goals, or they allow more modifications and changes where strategies and goals/objectives are more of a long-term orientation. These trends might be another reflection of the perceived instability of the business environment and firms actively adapting to it, either through broader and less goals/objectives, or by designing specific growth targets and strategies for the firm in the short term. The observed trends are good indirect testimonies as to the concerns coming from a perceived more instable environment. The reasons for the changes or modifications in firms' strategies from 2007 to 2014 tell even more about the perceived morose environment and a post-crisis period, to which firm adapts by aligning primarily to the external environment's threats. 


\section{Conclusions}

The present study has some limitations, mainly with respect to the samples of studied firms. This can be among the directions for future research. In addition, the innovative and competitive aspects could be further studied in more depth. Among the implications, for researchers as well as businesses, is the continuous feature over time with regard to aspects of the strategic behavior and its dimensions: the strategy formulation, the analysis and planning of the current capabilities, and the analysis and planning of the development of new capabilities. The pricing strategy also remains sustained over two periods, both in an environment of opportunities and in such of a post-crisis period.

Curiously, the strategic learning is likewise sustained through the two periods. Its presence is associated with the highly superior or superior strategic aggressiveness, of which the latter persists during the second period.

Nonetheless, the more turbulent environment has put its mark on other elements of Bulgarian firms' strategic behavior, both innovative and competitive, which clearly are not similar and sustained over the two types of environment. As implications for research and business are the trends regarding the goals/objectives of firms, the modifications or changes in firms' strategy, and the strategic actions that begin to precede strategic decisions. For these and other elements, there is a move from the long to the short term, to modifications less allowed, and simultaneously, to more permission of strategic actions to precede strategic decisions outside the short-term, most often explicitly documented strategies.

\section{References}

Abu-Rahma, A. M. (1999). The relationships among national culture, strategic aggressiveness, capability and financial performance: The case of banks in Jordan and the United States (Unpublished doctoral dissertation, College of Business Administration, United States International University).

Achua, C. F. (1992). Relationship between selected strategic project management factors and performance of project groups of manufacturing and/or service businesses (Unpublished doctoral dissertation, School of Business and Management, United States International University).

Al-Hadramy, A. (1992). General managers' personality characteristics and perception of environmental turbulence as determinants of rationality of choice in small firms (Unpublished doctoral dissertation, School of Business and Management, United States International University).

Ansoff, H. I. (1979). Strategic management. London: Macmillan.

Ansoff, H. I. (1987). The emerging paradigm of strategic behavior. Strategic Management Journal, 8(6), 501-515.

Ansoff, H. I. (1988). The new corporate strategy. New York: John Wiley.

Ansoff, H. I., \& McDonnell, E. J. (1990). Implanting strategic management (2nd ed.). New York: Prentice-Hall.

Ansoff, H. I., \& Sullivan, P. A. (1993a). Optimizing profitability in turbulent environments: A formula for strategic success. Long Range Planning, 26(5), 11-23.

Ansoff, H. I., \& Sullivan, P. A. (1993b) Empirical proof of a paradigmic theory of strategic success behaviors of environment serving organizations. International Review of Strategic Management, 4, 173-202.

Ansoff, H. I., \& McDonnell, E. J. (1984). Implanting strategic management. New York: Prentice-Hall.

Ansoff, H. I. (1965). Corporate strategy. New York: McGraw-Hill.

Ansoff, H. I., Sullivan, P. A., Antoniou, P., Chabane, H., Djohar, S., Jaja, R., ... Wang, P. (1993). Empirical proof of a paradigmic theory of strategic success behaviours on environment serving organizations. In D. E. Hussey (Ed.), International review of strategic management (pp. 173-203). New York: John Wiley.

Camelia, R. J. G. (1993). Perceived impact of different types of European Community regulations on performance of business firms in the Netherlands (Unpublished doctoral dissertation, School of Business and Management, United States International University).

Chabane, H. (1987). Restructuring and performance in Algerian state-owned enterprises: A strategic management study (Unpublished doctoral dissertation, School of Business and Management, United States International University). 
Chafie, M. (1992). The relationships between top management information system profiles, managerial capability and environmental turbulence (Unpublished doctoral dissertation, School of Business and Management, United States International University).

Chartier, C. T. (1998). Strategic leadership: Product and technology innovation in high-technology companies (Unpublished doctoral dissertation, College of Business Administration, United States International University).

Choi, D. R. (1993). The relationships between strategic factors and performance of diversified firms and their strategic business units in Japan (Unpublished doctoral dissertation, School of Business and Management, United States International University).

Coop, L. C. (1999). The relationship between decision style and power source used in decision-making and strategic success in Christian churches (Unpublished doctoral dissertation, College of Business Administration, United States International University).

Djohar, S. (1991). The relationships between strategic effectiveness, competitive efficiency and performance in Indonesian firms (Unpublished doctoral dissertation, School of Business and Management, United States International University).

Freidank, J. (1994). Managing transformational change in German business firms (Unpublished doctoral dissertation, School of Business and Management, United States International University).

Gabriel, S. N. (1996). An empirical assessment of a predictive theory of resistance to transformational change in environment-serving organizations (Unpublished doctoral dissertation, College of Business Administration, United States International University).

Gutu, J. M. (1989). An investigation of environmental dependence hypothesis in state-owned corporations (parastatals) in Kenya: A strategic management perspective (Unpublished doctoral dissertation, School of Business and Management, United States International University).

Han, Y. W. (1999). The relationship between environmental turbulence, top manager mindset, organization culture, power and performance in Korean firms (Unpublished doctoral dissertation, College of Business Administration, United States International University).

Hatziantoniou, P. (1986). The relationship of environmental turbulence, corporate strategic profile, and company performance (Unpublished doctoral dissertation, School of Business and Management, United States International University).

Hristova, M. (2007). Strategic management in a transition country: The case of Bulgaria (Ph.D. dissertation thesis defended in a joint Ph.D. programme (cotutelle) between University of Montesquieu-Bordeaux IV and Sofia University "St.Kliment Ohridski").

Hristova, M. (2009). Comparative analysis of the strategic behavior of enterprises in Bulgaria and France and of its impact on enterprises' performance (Post-doc research project, performed at the University of Montesquieu-Bordeaux IV and at the Sofia University "St.Kliment Ohrirdski”, under Fellowship Programme of the Bulgarian Ministry of Education and Science (2008-2009)).

Jaja, R. M. (1989). Technology and banking: The implications of technological change on the financial performance of commercial banks (Unpublished doctoral dissertation, School of Business and Management, United States International University).

Jihwan, Y. (2000). The relationships among environmental turbulence, strategic aggressiveness of information technology, organizational information technology capability, and organizational performance (Unpublished doctoral dissertation, University of Memphis).

Johannesson, J. (1994). The relationships among strategic intelligence aggressiveness, capability and the success of strategic intelligence function (Unpublished doctoral dissertation, College of Business Administration, United States International University).

Levitt, C. E. (1997). Acquisition and assimilation of management skills by Chinese light industrial firms: Soft technology transfer to a transnational economy (Unpublished doctoral dissertation, College of Business Administration, United States International University).

Lewis, A. O. (1989). Strategic posture and financial performance of the banking industry in California: A strategic management study (Unpublished doctoral dissertation, School of Business and Management, United States International University).

Lombriser, R. (1992). Impact of general manager leadership behavior on success of discontinuous strategic changes in thirty Swiss business firms (Unpublished doctoral dissertation, United States International University).

Mitiku, A. (1992). The relationship of general management capability with performance in state-owned industrial enterprises in Ethiopia: A strategic approach (Unpublished doctoral dissertation, School of Business and Management, United States International University). 
Moussetis, R. C. (1996). The relationships between legitimacy posture, rules of the game and performance of the firm (Unpublished doctoral dissertation, College of Business Administration, United States International University).

Salameh, T. T. (1987). Analysis and financial performance of the banking industry in United Arab Emirates: A strategic management study (Unpublished doctoral dissertation, School of Business and Management, United States International University).

Schulze, R. F. P. (1994). Differences of corporate management behavior to foster success of intrapreneurs in charge of incremental or discontinuous innovations (Unpublished doctoral dissertation, School of Business and Management, United States International University).

Sullivan, P. A. (1987). The relationship between proportion of income derived from subsidy and strategic performance of a Federal Agency under the commercial activities program (Unpublished doctoral dissertation, School of Business and Management, United States International University).

Taylor, J. (1992). Factors and behaviors associated with successful technology substitution decisions in the high turbulence environment (Unpublished doctoral dissertation, ProQuest Dissertations and Theses database).

Thabet, S. S. (1993). The relationship between strategic choice of technology and success of technology transfer to local firms in less developed countries: The case of Yemen (Unpublished doctoral dissertation, College of Business Administration, United States International University).

Thorsell, J. M. (1990). A framework for determination of strategies for general manager transformational development (Unpublished doctoral dissertation, School of Business and Management, United States International University).

Velten, T. (1997). The relationships between corporate general management behavior and the success of strategic portfolio management in German business firms (Unpublished doctoral dissertation, College of Business Administration, United States International University).

Wang, P. (1991). Determinants of perceptions of environmental managers (Unpublished doctoral dissertation, School of Business and Management, United States International University). 